\title{
AMY2A: A possible tumor-suppressor gene of 1p21.1 loss in gastric carcinoma
}

\author{
JI UN KANG ${ }^{1}$, SUN HOE KOO ${ }^{2}$, KYE CHUL KWON $^{2}$ and JONG WOO PARK ${ }^{2}$ \\ ${ }^{1}$ Department of Pathology, Columbia University Medical Center, New York, NY 10032, USA; ${ }^{2}$ Department of Laboratory \\ Medicine, Chungnam National University College of Medicine, Daejeon 301-721, Republic of Korea
}

Received October 29, 2009; Accepted December 30, 2009

DOI: 10.3892/ijo_00000628

\begin{abstract}
Homozygous deletions (HDs) are major genomic forces contributing to the development of many solid tumors. To identify critical tumor-suppressor loci involved in the pathogenesis of gastric carcinoma (GC), a high-resolution microarray-CGH was performed in a series of $27 \mathrm{GC}$ patients. On a genome-wide profile, five distinct HD ( $\log _{2}$ ratio <-1) loci, including 1p21.1, 2q21.1, 10q24.32, 13q34 and 15q11.2 were identified. These regions contained representative tumor-related genes, such as the FGF8 and NPM3 genes at $10 \mathrm{q} 24.32$, and the $L A M P 1$ gene at $13 \mathrm{q} 34$, which have been reported in connection with various tumors. The most frequent HD encompassed chromosome band 1p21.1 in 5 of $27 \mathrm{GC}$ cases $(18.5 \%)$. A hemizygous deletion $\left(-0.5<\log _{2}\right.$ ratio $\leq-1)$ or a single copy $\operatorname{loss}\left(\log _{2}\right.$ ratio $\left.<-0.25\right)$ from the 1p21.1 region was noted in $51.9 \%(14 / 27)$ and $88.9 \%(24 / 27)$ of GCs, respectively. A $30 \mathrm{~Kb} \mathrm{HD}$ of the $1 \mathrm{p} 21.1$ chromosomal region was shown to contain a potential candidate tumor-suppressor gene (TSG) of $A M Y 2 A$. Quantitative real time PCR analysis further confirmed complete loss of expression of the $A M Y 2 A$ gene located at the $1 \mathrm{p} 21.1$ region. We demonstrated that $A M Y 2 A$, a possible TSG, is frequently silenced in GC deletion 1p21.1. The identified gene could provide a basis for further functional validation and may lead to the identification of novel candidates for tumorigenesis and targeted therapies in GC.
\end{abstract}

\section{Introduction}

Gastric carcinoma (GC) is the second most common cause of cancer-related deaths in the world (1). GC is characterized by a complex pattern of cytogenetic and molecular genetic changes, and chromosomal aberrations are a major genomic force contributing to the development in GC.

Correspondence to: Dr Sun Hoe Koo, Chungnam National University Hospital, 640 Daesadong, Jung-Gu, Taejeon 301-721 South Korea

E-mail: shkoo@cnu.ac.kr

Key words: microarray CGH, gastric carcinoma, copy number loss, homozygous deletion, tumor suppressor gene, quantitative real time PCR
Bi-allelic loss, also called homozygous deletion (HD), is one of several known mechanisms leading to gene inactivation. In cancer genomes, such HDs can cause the inactivation of genes with tumor-suppressor activity and thus contribute to cancer development and progression (2). It has been proposed that inactivation of tumor-suppressor genes (TSGs) plays an important role in the development of many human solid tumors (3). Therefore, detection of specific gene deletions in tumor cells can lead to the identification of genes putatively involved in growth control and tumorigenesis.

Previous analyses of the GC genome with low-resolution chromosomal or BAC array-CGH have demonstrated several typical regions with genomic deletions. The most common HDs in GC have been repeatedly detected on 2q, 3p, 9p, 16q, $17 p$ and 20q (4-11). Many significant genes that map to these regions have previously been described to be deleted in GC (e.g., FHIT, CDKN2A/p16, RB1 and WWOX) (8-11) and are known to promote the carcinogenesis of GC, but little is known about the specific underlying genes that affect tumorigenesis in GC.

Array $\mathrm{CGH}$ is recognized as a successful tool for the analysis of chromosome copy-number alterations that may prove suitable for individualized diagnostic, prognostic and therapeutic decision-making. The significantly improved resolution of the array-based CGH technique permits highly accurate mapping of DNA copy number changes throughout the genome (2-5). Therefore, array-CGH is a promising starting point for the identification of novel candidate genes affected by genomic imbalances contributing to deregulation of the expression levels of TSGs.

Although many low-resolution chromosomal or arrayCGH-based copy number analyses of GC primary tumors have been reported, including our own, and have successfully identified a series of copy-number changes (4-13), few possible target genes for these alterations have been determined, suggesting that various critical genes for the pathogenesis of GC remain to be identified.

In this study we therefore employed a high-resolution array-CGH to identify critical candidate TSGs that could be important mediators in the formation or progression of GC.

\section{Materials and methods}

Study materials. Two early gastric carcinomas (EGC) and 25 advanced gastric carcinomas (AGC) were selected for array- 
CGH analysis from the Department of General Surgery at Chungnam National University Hospital in Taejeon, Korea. The histopathologic classification was based on the World Health Organization. Tumor staging was in accordance with the International Union Against Cancer (UICC) recommendations (14). The demographic and pathologic data, including age, gender, lymph node metastasis, and the tumor stage were obtained by a review of the medical records.

Tissue preparation. DNA was extracted from fresh frozen tissues of AGC and micro-dissected cells from EGC. Hematoxylin and eosin-stained sections for each sample were graded and micro-dissected under the guidance of a gastric pathologist. Micro-dissected samples containing at least $70 \%$ cancer cells were digested from the frozen tissue or microdissected cells with a lysis buffer, adding $10 \mathrm{mg} / \mathrm{ml}$ of proteinase $\mathrm{K}$, incubating the samples overnight at $55^{\circ} \mathrm{C}$, removing the RNA with RNAse, precipitating the unnecessary proteins, and aliquoting the DNA from the supernatants followed by washing and suspending the DNA. The genomic DNA was extracted using a Genomic DNA purification kit (Promega, Madison, WI, USA).

Array-CGH. Array-CGH was performed using the MacArray ${ }^{\mathrm{TM}}$ Karyo 1.4 K BAC-chip (Macrogen, Seoul, Korea) (15-19). The information on each individual clone was obtained from the UCSC Genome Bioinformatics database [http:// genome.ucsc.edu; Build 36, Version Mar. 2006 (hg18)]. The locus specificities of the chosen clones were confirmed by removing multiple loci-binding clones individually under standard fluorescence in situ hybridization (FISH) (20). These clones were prepared using the conventional alkaline lysis method to obtain BAC DNA. The arrays were manufactured using an OmniGrid arrayer (GeneMachine, San Carlos, CA, USA) using a 24-pin format. BAC clones were represented on an array as triplicated spots and each array was pre-scanned using a GenePix 4200A scanner (Axon Instruments, Foster City, CA, USA) for proper spot morphology. The array-CGH experiment, imaging and data analysis were carried out as described earlier (19). Briefly, $500 \mathrm{ng}$ of tumor and reference DNA were labeled with $\mathrm{Cy} 5$ and $\mathrm{Cy} 3$, respectively, using a Bioprime labeling kit (Invitrogen, Carlsbad, CA, USA). Array hybridization was carried out for $48 \mathrm{~h}$ at $37^{\circ} \mathrm{C}$. After hybridization, array slides were scanned on a GenePix 4200A two-color fluorescent scanner (Axon Instruments, Union City, CA, USA); quantification was performed using GenePix software (Axon Instruments).

We applied Lowess normalization, a form of smoothing adjustment that removes intensity-dependent variations in dye bias. Spot quality criteria were set as foreground-tobackground $>3.0$ and standard deviation of triplicates $<0.2$. The breakpoint detection and status assignment of genomic regions was performed by GLAD software (21). The average $\log _{2}$ Cy3/Cy5 signal ratios of the triplicate BAC clones were calculated for each sample, and \pm 0.25 ( $\log _{2}$ ratio) was used as a threshold for defining the copy number increases (gains) and decreases (losses). Homozygous deletion of clones was defined when the intensity ratios were $<-1$ in the $\log _{2}$ scale (22-24). This threshold value was defined empirically as a value 3 -fold that of the standard deviation calculated from
Table I. Demographic data for patients with 27 gastric carcinomas.

\begin{tabular}{|c|c|}
\hline Characteristic & Number (\%) \\
\hline \multicolumn{2}{|l|}{ Gender } \\
\hline Male & $21(77.8)$ \\
\hline Female & $6(22.2)$ \\
\hline \multicolumn{2}{|l|}{ Age $(\mathrm{M} \pm \mathrm{SD})$} \\
\hline$\leq 65$ & $11(40.7)$ \\
\hline$>65$ & $16(59.3)$ \\
\hline \multicolumn{2}{|c|}{ Borrmann's type } \\
\hline $\mathrm{AGC}^{\mathrm{a}}$ & $25(92.6)$ \\
\hline $\mathrm{EGC}^{\mathrm{b}}$ & $2(7.4)$ \\
\hline \multicolumn{2}{|c|}{ WHO differentiation } \\
\hline $\mathrm{WD}^{\mathrm{c}}$ & $3(11.1)$ \\
\hline $\mathrm{MD}^{\mathrm{d}}$ & $10(37.0)$ \\
\hline $\mathrm{PD}^{\mathrm{e}}$ & $14(51.9)$ \\
\hline \multicolumn{2}{|c|}{ pTNM classification ${ }^{f}$} \\
\hline \multicolumn{2}{|c|}{ Tumor status } \\
\hline pT1 & $10(37.0)$ \\
\hline pT2 & $9(33.3)$ \\
\hline pT3 & $5(18.5)$ \\
\hline pT4 & $3(11.1)$ \\
\hline \multicolumn{2}{|c|}{ Lymph node status } \\
\hline $\mathrm{Nx}$ & $3(11.1)$ \\
\hline N0 & $7(25.9)$ \\
\hline N1 & $6(22.2)$ \\
\hline $\mathrm{N} 2$ & $8(29.6)$ \\
\hline N3 & $3(11.1)$ \\
\hline \multicolumn{2}{|c|}{ Metastatic status } \\
\hline Mx & $2(7.4)$ \\
\hline M0 & $22(81.5)$ \\
\hline M1 & $3(11.1)$ \\
\hline \multicolumn{2}{|l|}{ Tumor stage } \\
\hline I & $8(29.6)$ \\
\hline II & $9(33.3)$ \\
\hline III & $7(25.9)$ \\
\hline IV & $3(11.1)$ \\
\hline
\end{tabular}

${ }^{\mathrm{a}} \mathrm{AGC}$, advanced gastric cancer; ${ }^{\mathrm{b}} \mathrm{EGC}$, early gastric cancer; ${ }^{\mathrm{c}} \mathrm{WD}$, well differentiated; ${ }^{\mathrm{d}} \mathrm{MD}$, moderately differentiated; ${ }^{\mathrm{e}} \mathrm{PD}$, poorly differentiated, ${ }^{\mathrm{f}} \mathrm{pTNM}$, tumor-node-metastasis.

30 normal males to normal females in hybridization experiments. The software MAC viewer (v1.6.6), CGH-Explorer 2.55 and Avadis 3.3 Prophetic were used for graphical illustration and image analysis of array-CGH data. A multiple testing correction [Benjamini-Hochberg false discovery rate (FDR)] was applied to correct for the high number of false positive calls. The R 2.2.1 package of the Bioconductor Project (http://www.bioconductor.org) was used for detection of the frequency of gain or loss and statistical analysis. 
Table II. Overview of 5 homozygous deletion regions detected by array-CGH in 27 gastric carcinomas.

\begin{tabular}{|c|c|c|c|c|c|c|}
\hline $\begin{array}{l}\text { Cytogenetics } \\
\text { locations }\end{array}$ & $\begin{array}{l}\text { Bac start } \\
\text { of the HD }\end{array}$ & $\begin{array}{c}\text { Bac end } \\
\text { of the HD }\end{array}$ & $\begin{array}{l}\text { Size }(\mathrm{kb}) \\
\text { of the } \mathrm{HD}^{\mathrm{a}}\end{array}$ & $\begin{array}{c}\text { Possible } \\
\text { target genes }\end{array}$ & $\begin{array}{l}\% \text { of loss } \\
\text { in } \mathrm{GCs}^{\mathrm{b}}\end{array}$ & $\begin{array}{l}\% \text { of } \mathrm{HD} \\
\text { in } \mathrm{GCs}^{\mathrm{c}}\end{array}$ \\
\hline $1 \mathrm{p} 21.1$ & $103,961,840$ & $103,992,000$ & 30,160 & $A M Y 2 A$ & $88.9 \%(24 / 27)$ & $18.5 \%(5 / 27)$ \\
\hline $2 q 21.1$ & $130,422,046$ & $130,519,616$ & 97,570 & & $96.3 \%(26 / 27)$ & $3.7 \%(1 / 27)$ \\
\hline $10 \mathrm{q} 24.32$ & $103,451,002$ & $103,545,553$ & 94,551 & $F G F 8, N P M 3, M G E A 5$ & $22.2 \% \quad(6 / 27)$ & $7.4 \%(2 / 27)$ \\
\hline $13 q 34$ & $113,034,986$ & $113,108,890$ & 73,904 & $L A M P 1, G R T P 1$ & $11.1 \% \quad(3 / 27)$ & $3.7 \%(1 / 27)$ \\
\hline $15 q 11.2$ & $22,856,147$ & $22,956,737$ & 100,590 & & $33.3 \% \quad(9 / 27)$ & $3.7 \%(1 / 27)$ \\
\hline
\end{tabular}

${ }^{a}$ Genomic positions were retrieved from the UCSC Genome browser web page [http://genome.cse.ucsc.edu; Build 36, Version Mar. 2006 (hg18)]. ${ }^{b}$ Alterations were defined by $\log _{2}$ ratio thresholds of -0.25 for copy number loss. Using this threshold, we generated a frequency table. ${ }^{c}$ Alterations were defined by $\log _{2}$ ratio thresholds of -1 for copy number homozygous deletion.

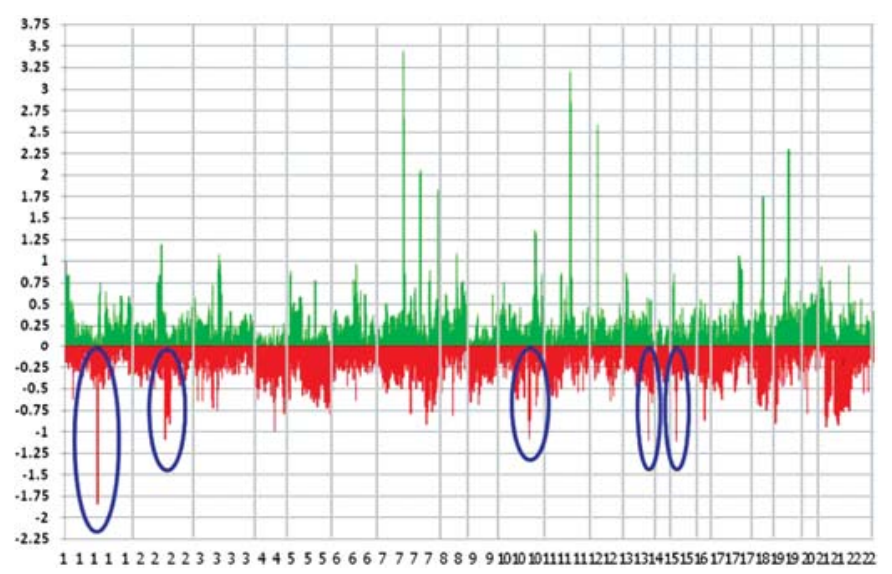

Figure 1. Frequency of chromosomal copy number changes in the 27 GC cases. Five homozygous deletion (HD) regions, including 1p11.2, 2q21.1, $10 \mathrm{q} 24.32,13 \mathrm{q} 34$ and $15 \mathrm{q} 11.2$, are highlighted in blue. $\log _{2}$ ratios for all clones were plotted based on the chromosome position, with the vertical dotted bars representing the separation of chromosomes. The clones were ordered from the $1 \mathrm{p}$ telomere on the left to the $22 \mathrm{q}$ telomere on the right. Gains and losses are shown as green and red color bars, respectively.

Quantitative real-time PCR analysis ( $Q-R T-P C R)$. Q-RT-PCR analysis was conducted to validate the array $\mathrm{CGH}$ results using the ABI PRISM 7900HT sequence detection system and TaqMan Gene Expression assays according to the manufacturer's instructions (Applied Biosystems, Foster City, CA, USA). The 2-primer/TaqMan probe combinations were designed based on sequences from the NCBI public database, and as follows: sense for $A M Y 2 A$, GTGGAAGTTA CTTCAACCCTGGAA; and anti-sense for AMY2A, ATATT TACCATCATTGAAATCCCATCCA. Amplifications were performed using the Universal Master Mix (Applied Biosystems) and cycling conditions of $15 \mathrm{sec}$ of denaturing time $\left(95^{\circ} \mathrm{C}\right)$ and $1 \mathrm{~min}$ of annealing/amplification time $\left(60^{\circ} \mathrm{C}\right)$ for 40 cycles after an initial activation step of $10 \mathrm{~min}$ at $95^{\circ} \mathrm{C}$. All samples were amplified in triplicate and data were analyzed using Sequence Detector software (Applied Biosystems). We quantified sample DNAs using standard curves generated using three reference DNAs. All data analysis used ArrayAssist ${ }^{\circledR}$ (Stratagene, La Jolla, CA, USA) and R (version 2.7.2). The correlation between the BAC chip and Q-RT-PCR data was performed by Pearson correlation analysis $(\mathrm{P}<0.05)$. Normalized normal human pooled genomic DNAs (Promega) were used as reference DNAs.

\section{Results}

Homozygous deleted chromosomal regions in GCs by genome-wide array-CGH. High-density genomic arrays were employed to characterize common regions throughout the whole genome deletion in a series of $27 \mathrm{GC}$ patients. The clinicopathologic data for the $27 \mathrm{GC}$ cases are summarized in Table I. Since the most common genetic aberrations had already been identified in GCs, we focused on more remarkable patterns of chromosomal alterations, such as HDs, which are likely to be landmarks of TSGs in GC.

On a genome-wide profile, five distinct lost genomic loci were identified as candidate regions for $\mathrm{HD}\left(\log _{2}\right.$ ratio <-1) in 6 of the $27 \mathrm{GC}$ cases [22\% (6/27)]. Only well-defined HDs, excluding alterations that spanned several mega-bases or whole chromosome arms, were included. The 5 HD loci of the 27 GC cases are shown in Table II.

The most frequently deleted HDs of the cases were observed on $1 \mathrm{p} 21.2$ [18.5\% (5/27)] followed by $10 \mathrm{q} 24.32$ [7.1\% (2/27)], 2q21.1, 13q34, and 15q11.2 [3.7\% (1/27)]. Several such alterations corresponded to known cancerrelated genes, including the $F G F 8$ and NPM3 genes at $10 \mathrm{q} 24.32$, and the $L A M P 1$ gene at $13 \mathrm{q} 34$. In addition, we identified possible candidate TSGs, namely the $A M Y 2 A$ (1p21.2), MGEA5 (10q24.32) and GRTP1 genes at 13q34 that previously had not been assumed to play a pathogenic role in GCs. The frequency of chromosomal copy number changes with 5 HD loci in the 27 GCs are shown in Fig. 1.

Homozygous deletion and high frequency loss at 1p21.1 region in GCs. Genome-wide array-CGH analysis showed that 25 of 27 cases $(92.6 \%)$ of GCs involved copy number losses $\left(\log _{2}\right.$ ratio $\left.<-0.25\right)$ on the short arm of chromosome 1 . The minimal common region identified by the array-CGH was located between BAC 22_M23 and BAC 22_P12.

A more detailed analysis of chromosome 1p identified 3 distinct regions of alteration across the chromosome. One 


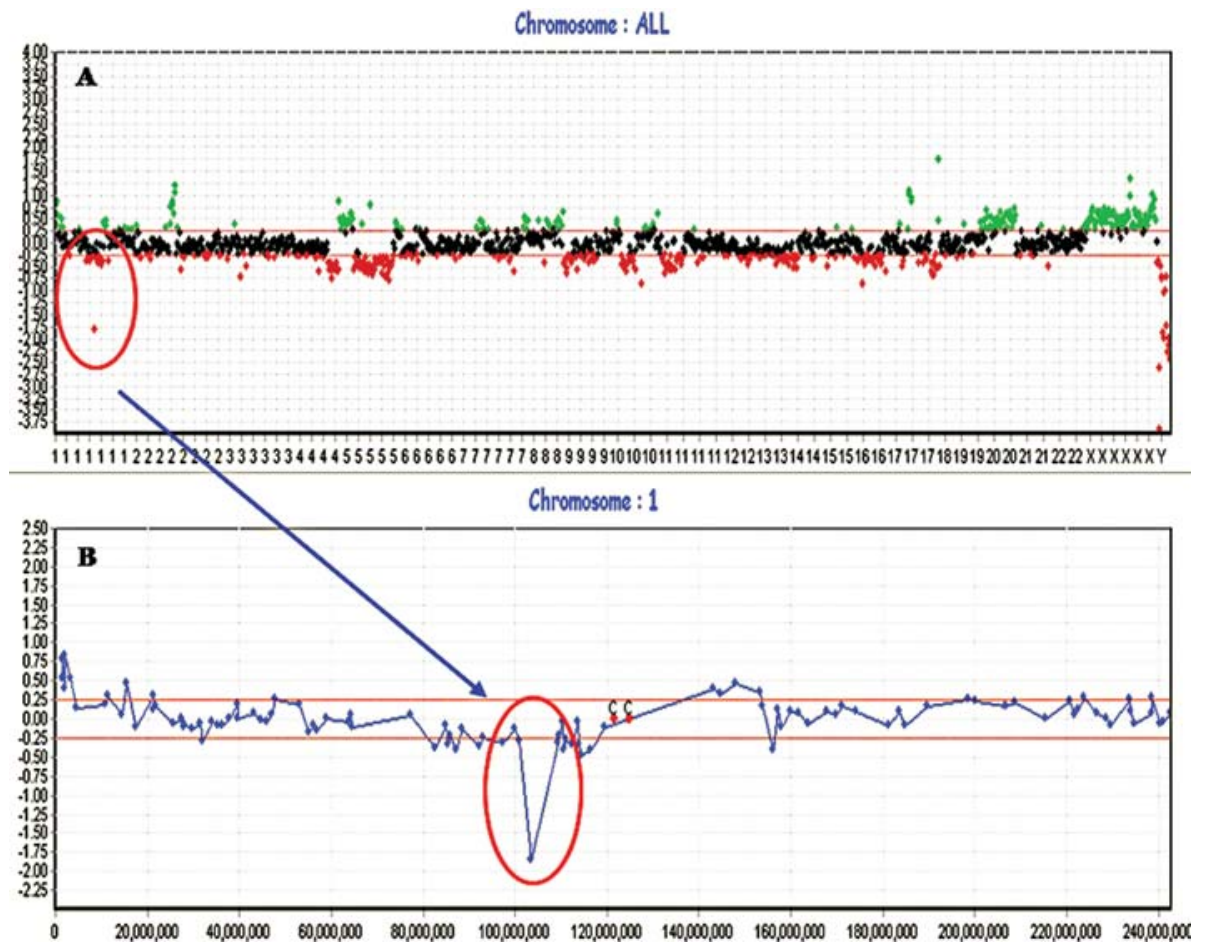

Figure 2. (A) Results of array-based CGH analysis from a patient sample (tumor 27). Normalized $\log _{2}$ signal intensity ratios of the 1,440 clones were plotted

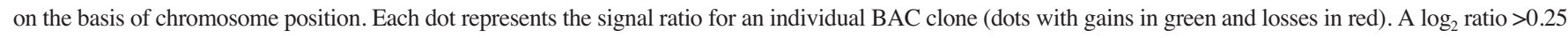
represents a genomic copy number gain, and a $\log _{2}$ ratio $<-0.25$ represents a genomic copy number loss. Clones are in the order from chromosome $1 \mathrm{p}$ to $22 \mathrm{q}$. (B) Genomic profiles of chromosome 1, including HDs at 1p21.1 from a tumor (T27). Vertical lines indicate the lowest locus of chromosome 1 in the BAC clone containing the $A M Y 2 A$ gene. $\log _{2}$ ratio was <-1 in this BAC clone, suggesting that HD occurs at the $A M Y 2 A$ gene locus.

region spanning approximately $82-77 \mathrm{kbp}$ on $1 \mathrm{p} 32.3-\mathrm{p} 31.1$ containing candidate TSG, namely Disabled I $(D A B 1)$ was detected in $29.6 \%(8 / 27)$ of the GC cases.

The second candidate locus spanned $100 \mathrm{kbp}$, mapping at $1 \mathrm{p} 22.1$, and harbored putative TSG of growth factor independent-1 (GFI1). The single copy number loss at $1 \mathrm{p} 22.1$ was noted in $22.2 \%(6 / 27)$ of the cases. Five of 6 cases at the $1 \mathrm{p} 22.1$ losses were found in high-stage tumors (III and IV; data not shown).

The third interval spans, 78-30 kbp on 1p21.3-p21.1, comprised the possible TSGs of the $\alpha$ amylase $(A M Y 2 A)$ and dihydropyrimidine dehydrogenase $(D P Y D)$ genes $[92.6 \%$ $(25 / 27)]$. More specifically, HDs $\left(\log _{2}\right.$ ratio $\left.<-1\right)$ or hemizygous deletions $\left(-0.5<\log _{2}\right.$ ratio $\left.\leq-1\right)$ at the $1 \mathrm{p} 21.1$ region were detected in $18.5 \%(5 / 27)$ and $51.9 \%$ (14/27), respectively. Representative genome profiles of HDs at $1 \mathrm{p} 21.1$ are shown in Fig. 2. Whole genome profiles from a GC case (tumor 27) (A) are shown in the upper portion and individual chromosome profiles with HDs at the 1p21.1 region (B) are presented in more detail below (T27). Fig. 3A shows a weighted frequency $(\%)$ diagram for chromosome 1 with HDs at 1p21.1 from all of the $27 \mathrm{GC}$ cases and an example of an individual profile with cases 5, 19, 24, 26 and 27 showing HDs from the same region in $27 \mathrm{GCs}$ is presented in Fig. 3B.

Quantitative real-time PCR analysis. To delineate the consequences of HDs, we subsequently performed Q-RT-PCR analysis of the $A M Y 2 A$ gene at the $1 \mathrm{p} 21.1$ region, which had been detected as an HD $\left(\log _{2}\right.$ ratio <-1) by analysis on the array-CGH. Twenty-two tumors with 1p21.1 loss and three patients without this loss were analyzed. The value of array$\mathrm{CGH}$ was depicted by linear ratios and $\mathrm{N}$-values were delineated in Q-RT-PCR. Although the absolute values of the selected gene were different between the two analyses, statistically significant correlation was observed between the two data sets $(\mathrm{P}<0.05)$. The correlation coefficient between the gene expression levels in Q-RT-PCR and array-CGH analysis for the gene $(A M Y 2 A)$ was $0.459(\mathrm{P}=0.021)$. Twenty-two patients with $1 \mathrm{p} 21.1$ loss showed complete loss of expression of $A M Y 2 A$ compared with three normal cases (Fig. 4A). Fig. 4B represents the scatter plot analysis of all data points for the $A M Y 2 A$ gene by array CGH and Q-RT-PCR analysis in GC cases.

\section{Discussion}

Homozygous deletions (HDs) provide an important resource for identifying the location of candidate TSGs (25). The importance of such deletions has been demonstrated in previous studies, but little is known about the specific underlying genes that could be important mediators in tumor initiation or progression.

Array-CGH has been recognized as a successful tool for evaluation of the whole genome. One of the advantages of array-CGH is the ability to convincingly detect HDs, an alteration that strongly suggests the presence of a TSG in the deleted regions (26). Using a whole genomic profile, we identified five HD $\left(\log _{2}\right.$ ratio <-1) loci, including $1 \mathrm{p} 21.1$, $2 q 21.1,10 q 24.32,13 q 34$ and $15 q 11.2$, with detection of at least one $\mathrm{HD}$ in $27 \mathrm{GC}$ patients. 


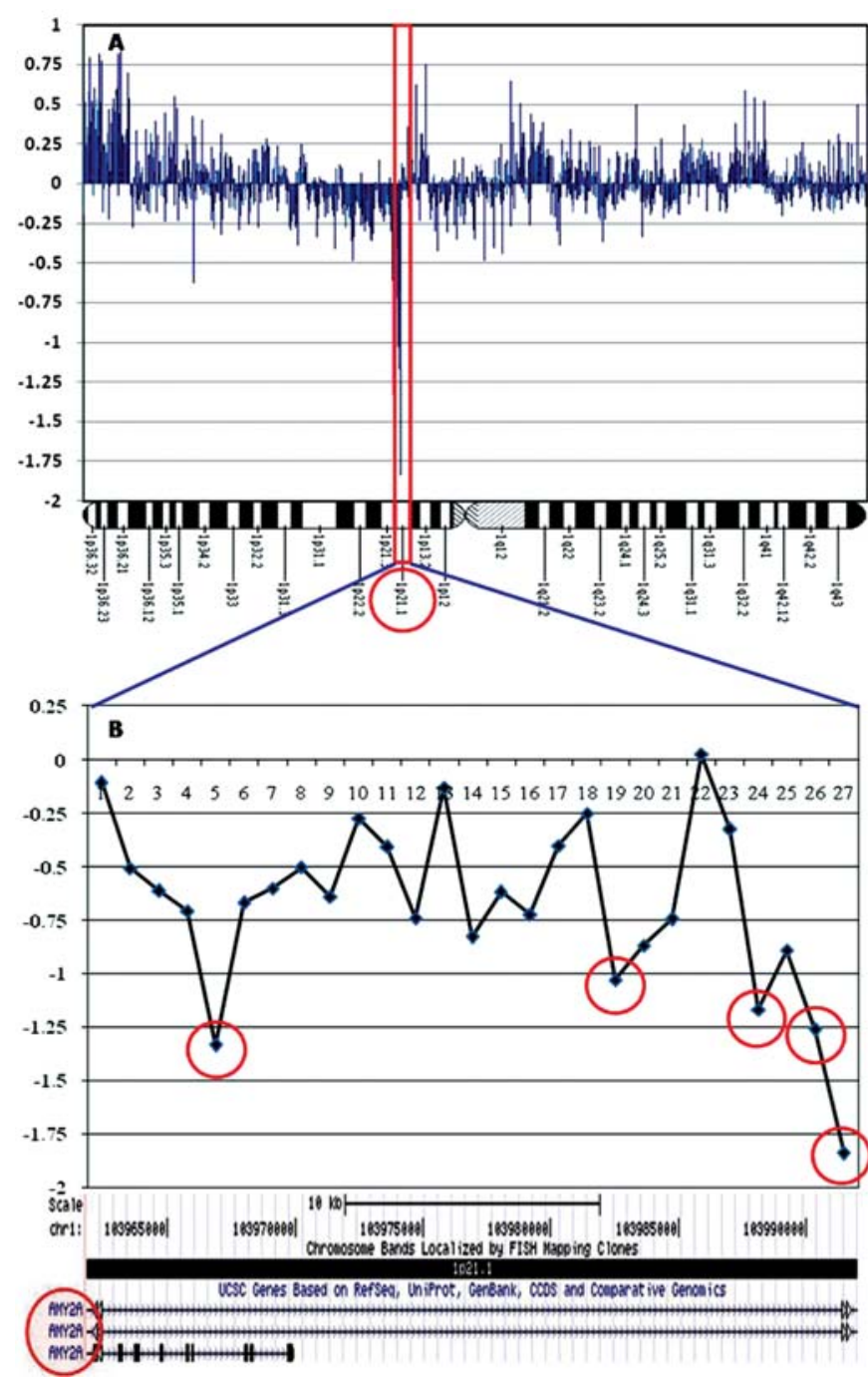

Figure 3. (A) Weighted frequency (\%) diagram for chromosome 1 with HDs at 1 p21.1 from all of the 27 GCs. The HDs at 1p21.1 are highlighted in red. In the intensity ratio profiles, the $\mathrm{x}$-axis represents the map position of the corresponding clone and the intensity ratios were assigned to the y-axis. (B) Individual profiles with cases 5, 19, 24, 26 and 27 showing HDs at $1 \mathrm{p} 21.1$ region in $27 \mathrm{GCs}$ (circled in red). The schematic presentation of cytogenetic bands, as well as a map position, is shown below the plot. HDs are clearly seen at chromosome 1p21.1 (AMY2A).

HD of $2 q 21.1$ region was observed in 27 GC cases, albeit infrequently [1/27 (3.7\%)]. However, this region was lost in the majority of GC cases [26/27 (96.3\%)] without homozygous loss, suggesting that the $2 \mathrm{q} 21.1$ region contains multiple GC suppressor genes and/or genomic features which are fragile during gastric carcinogenesis. Further studies are needed to validate this hypothesis.

Homozygous deletion was also detected at 10q24.32 $[7.1 \%(2 / 28)]$, containing several putative cancer-related genes (FGF8, NPM3 and MGEA5). HD at this region has not been described in GC thus far, but is commonly found in other cancers (27-30). Bashyam et al (27) showed an HD at $10 \mathrm{q} 24$ in pancreatic cancer and Narayan et al (28) demonstrated a hemizygous deletion at 10q24 in cervical cancer. Loss of heterozygosity $(\mathrm{LOH})$ or microsatellite instability (MSI) was also reported from the same region. Hui et al (29) showed frequent loss at 10q24.32-26.2 regions

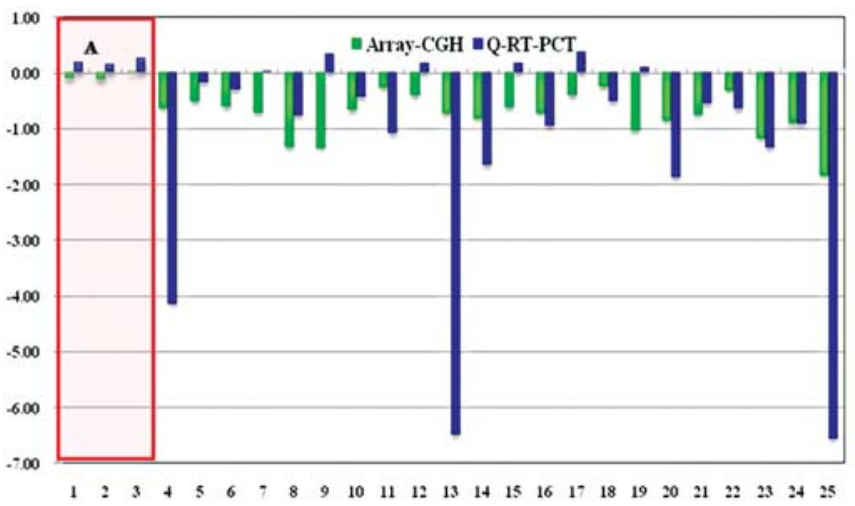

B - AMY2A[Logratio]_Q-RT-PCR -Linear(ANY2A[Logratio]_Q-RT-PCR)

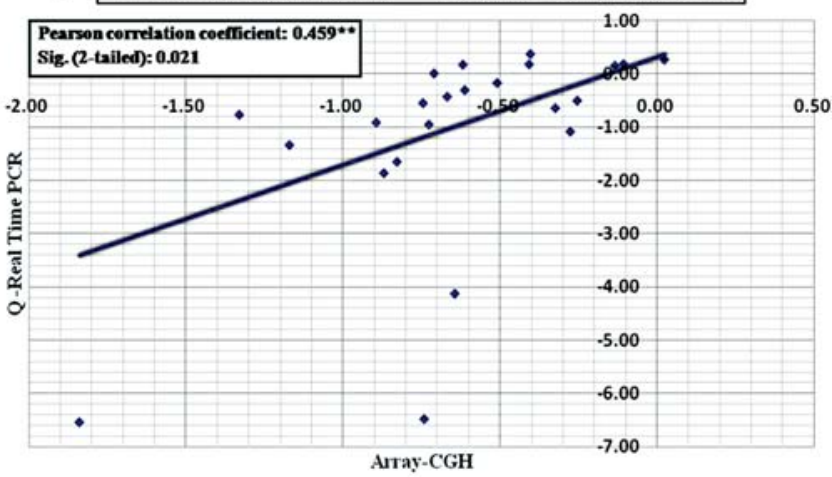

Figure 4. (A) The results of quantitative real-time PCR (blue bar) were compared with those of the array CGH (green bar) for the AMY $2 A$ candidate gene. The horizontal axis indicates sample number and the vertical axis indicates $\log _{2}$ ratio of copy number changes. Three patients without loss at $1 \mathrm{p} 21.1$ are shaded in red. (B) The scatter plot analysis of all data points of the gene $A M Y 2 A$ by Array CGH ( $X$ axis) and Q-RT-PCR ( $Y$ axis) analysis in $\mathrm{GC}$ patients. Each dark square is the $\log _{2}$ ratio value of the clone containing $A M Y 2 A$ gene for one case. The correlation coefficients (r) and P-value between the two data sets are given in the upper left corner of the figure.

in medulloblastomas and the high frequency $(74 \%)$ of $\mathrm{LOH}$ at $10 \mathrm{q} 24$ in small cell lung cancer has also been described (30). Taken together, these and our own results suggest that inactivation of TSGs within this region may play a critical role in development or progression of a variety of neoplasms, including GC.

A 74-kbp HD at the $13 q 34$ region in GC is described here for the first time and contains several possible candidate TSGs, such as, LAMPI and GRTP1, which have not been previously reported as deletions in GCs. However, loss at another region of $13 \mathrm{q}$ is commonly identified in GCs $(31,32)$. Wozniak et al (31) demonstrated that genomic losses often affected $13 q$ with two minimal overlapping regions at $13 q 14.11-q 14.2$ and $13 q 32.3-q 33.1$ in gastrointestinal stromal tumors and the high frequency of $\mathrm{LOH}(83 \%)$ at the $13 \mathrm{q}$ region has also been reported in GC cases (32). These results suggest that this region could be the site of a candidate TSG in GC.

The HDs at 15q11.2 (7.1\%, 2/28) do not encompass any known TSGs. However, a high frequency of single-copy loss or hemizygous deletion from the same region was detected in $33.3 \%(9 / 27)$ and $7.1 \%(2 / 28)$, respectively, suggesting that this might be affected in tumorigenesis of GC.

Previous low-resolution cytogenetic or $\mathrm{LOH}$ analyses have implicated the short arm of chromosome 1 as having a major 
role in the initiation and/or progression of GC (31,33-35), suggesting the presence of multiple TSGs. Derre et al (33) documented that consistent DNA losses on the short arm of chromosome 1 is the most striking feature of malignant gastrointestinal stromal tumors and Wozniak et al (31) reported that the deletion of $1 \mathrm{p}(1 \mathrm{p} 36.32-1 \mathrm{p} 35.2,1 \mathrm{p} 34.1$ and $1 \mathrm{p} 22.1-$ $1 \mathrm{p} 21.3)$ was the second most frequent chromosomal imbalance $(59 \%)$, with predominance in gastrointestinal stromal tumors.

In the present study, the loss of the short arm of chromosome 1 detected in 25 of 27 (92.6\%) GC cases, revealing the following 3 minimal overlapping regions: 1p32.2-p31.1 (82-77 kbp), $100 \mathrm{kbp}$ (mapping at 1p22.1) and 1p21.3-p21.1 (78-30 kbp). Among these regions of imbalance, loss at $1 \mathrm{p} 21.1$ seems particularly interesting, because a single-copy number loss $\left(\log _{2}\right.$ ratio <-0.25) was noted in $88.9 \%(24 / 27)$ of the cases. More specifically, HDs at $1 \mathrm{p} 21.1$ were identified in 5 of $27(18.5 \%)$ cases. This region has a $30 \mathrm{kbp}$ gene-specific copy number loss comprising the one potential candidate TSG of the $A M Y 2 A$ gene, coding for salivary and pancreatic amylases. The estimated extent of the HD was $30 \mathrm{kbp}$; the $A M Y 2 A$ gene is the only gene within that region, and it must represent the actual and sole target for HDs in GC. Although, the $A M Y 2 A$ gene has not been previously documented as being deleted in GC, lack of the $A M Y 2 A$ gene has been described in connection with human cancers. Fibach et al (36) described that leukemia represents a deficiency of pancreatic enzymes leading to a state of arrested development in leukocytes and lacking mature leukocytes, to compensate, the body continues producing more pro-leukocytes, as is found in leukemia. Furthermore, the lack of fetal amylase has been suggested as the cause of cancer eclampsia and use of amylase along with trypsin was proposed for cancer treatment (37). These findings support our hypothesis that $A M Y 2 A$ gene may have potential for a tumor suppressor of GC. Therefore, an HD of the $A M Y 2 A$ gene seems to be involved in carcinogenesis of human cancers, including that of GC. Q-RT-PCR analysis further confirmed complete loss of expression of the $A M Y 2 A$ gene located at 1 p21.1 region. Further functional and biological studies are expected to validate and to evaluate the role of the $A M Y 2 A$ gene as a novel candidate TSGs in GC in larger series and on multiple samples.

In the study presented herein, we successfully identified the $A M Y 2 A$ gene as having the greatest potential as a $1 \mathrm{p} 21.1$ HD target in GC. Frequent detection of reduced copy number of the $A M Y 2 A$ gene implicates it as suppressors of GC tumorigenesis and might be a good candidate as a therapeutic target.

\section{Acknowledgements}

This work was supported by grant No. R11-2002-100-00000-0 from ERC program of the Korea Science and Engineering Foundation.

\section{References}

1. Parkin DM, Pisani P and Ferlay J: Global cancer statistics. CA Cancer J Clin 49: 33-64, 1999.
2. Giefing M, Arnemann J, Martin-Subero JI, Nieländer I, Bug S, Hartmann S, Arnold N, Tiacci E, Frank M, Hansmann ML, Küppers R and Siebert R: Identification of candidate tumour suppressor gene loci for Hodgkin and Reed-Sternberg cells by characterisation of homozygous deletions in classical Hodgkin lymphoma cell lines. Br J Haematol 142: 916-924, 2008.

3. Hoebeeck J, Michels E, Menten B, Van Roy N, Eggert A, Schramm A, De Preter K, Yigit N, De Smet E, De Paepe A, Laureys G, Vandesompele J and Speleman F: High resolution tiling-path BAC array deletion mapping suggests commonly involved 3p21-p22 tumor suppressor genes in neuroblastoma and more frequent tumors. Int J Cancer 120: 533-538, 2007.

4. Takada H, Imoto I, Tsuda H, Nakanishi Y, Ichikura T, Mochizuki H, Mitsufuji S, Hosoda F, Hirohashi S, Ohki M and Inazawa J: ADAM23, a possible tumor suppressor gene, is frequently silenced in gastric cancers by homozygous deletion or aberrant promoter hypermethylation. Oncogene 24: 8051-8060, 2005.

5. Takada H, Imoto I, Tsuda H, Sonoda I, Ichikura T, Mochizuki H, Okanoue T and Inazawa J: Screening of DNA copy-number aberrations in gastric cancer cell lines by array-based comparative genomic hybridization. Cancer Sci 96: 100-110, 2005.

6. Takada H, Imoto I, Tsuda H, Nakanishi Y, Sakakura C, Mitsufuji S, Hirohashi S and Inazawa J: Genomic loss and epigenetic silencing of very-low-density lipoprotein receptor involved in gastric carcinogenesis. Oncogene 25: 6554-6562, 2006.

7. Mattar R, Nonogaki S, Silva C, Alves V and Gama-Rodrigues JJ: $\mathrm{P} 53$ and $\mathrm{Rb}$ tumor suppressor gene alterations in gastric cancer. Rev Hosp Clin Fac Med Sao Paulo 59: 172-180, 2004.

8. Akama Y, Yasui W, Kuniyasu H, Yokozaki H, Akagi M, Tahara H, Ishikawa T and Tahara E: Genetic status and expression of the cyclin-dependent kinase inhibitors in human gastric carcinoma cell lines. Jpn J Cancer Res 87: 824-830, 1996.

9. Huiping C, Kristjansdottir S, Bergthorsson JT, Jonasson JG, Magnusson J, Egilsson V and Ingvarsson S: High frequency of LOH, MSI and abnormal expression of FHIT in gastric cancer. Eur J Cancer 38: 728-735, 2002.

10. Feakins RM, Nickols CD, Bidd $\mathrm{H}$ and Walton SJ: Abnormal expression of $\mathrm{pRb}, \mathrm{p} 16$, and cyclin D1 in gastric adenocarcinoma and its lymph node metastases: relationship with pathological features and survival. Hum Pathol 34: 1276-1282, 2003.

11. Aqeilan RI, Kuroki T, Pekarsky Y, Albagha O, Trapasso F, Baffa R, Huebner K, Edmonds P and Croce CM: Loss of WWOX expression in gastric carcinoma. Clin Cancer Res 10: 3053-3058, 2004

12. Koo SH, Kwon KC, Shin SY, Jeon YM, Park JW, Kim SH and Noh SM: Genetic alterations of gastric cancer: comparative genomic hybridization and fluorescence in situ hybridization studies. Cancer Genet Cytogenet 117: 97-103, 2000.

13. Gunawan B, von Heydebreck A, Sander B, Schulten HJ, Haller F, Langer C, Armbrust T, Bollmann M, Gasparov S, Kovac D and Füzesi L: An oncogenetic tree model in gastrointestinal stromal tumours (GISTs) identifies different pathways of cytogenetic evolution with prognostic implications. J Pathol 211: 463-470, 2007.

14. Tsendsuren T, Jun SM and Mian XH: Usefulness of endoscopic ultrasonography in preoperative TNM staging of gastric cancer. World J Gastroenterol 12: 43-47, 2006.

15. Kim JI, Ju YS, Park H, Kim S, Lee S, Yi JH, Mudge J, Miller NA, Hong D, Bell CJ, Kim HS, Chung IS, Lee WC, Lee JS, Seo SH, Yun JY, Woo HN, Lee H, Suh D, Lee S, Kim HJ, Yavartanoo M, Kwak M, Zheng Y, Lee MK, Park H, Kim JY, Gokcumen O, Mills RE, Zaranek AW, Thakuria J, Wu X, Kim RW, Huntley JJ, Luo S, Schroth GP, Wu TD, Kim H, Yang KS, Park WY, Kim H, Church GM, Lee C, Kingsmore SF and Seo JS: A highly annotated whole-genome sequence of a Korean individual. Nature 460: 1011-1015, 2009.

16. Kim JI, Lee JH, Seo JS, Hwang KT, Han W, Cho J, Lee JW, Ko E, Kim EK, Jung SY, Jeong EM, Bae JY, Kang JJ, Yang SJ, Kim SW and Noh DY. Genomic copy number alterations as predictive markers of systemic recurrence in breast cancer. Int $\mathbf{J}$ Cancer 123: 1807-1815, 2008.

17. Choe J, Kang JK, Bae CJ, Lee DS, Hwang D, Kim KC, Park WY, Lee JH and Seo JS: Identification of origin of unknown derivative chromosomes by array-based comparative genomic hybridization using pre- and postnatal clinical samples. J Hum Genet 52: 934-942, 2007. 
18. Choi YW, Choi JS, Zheng LT, Lim YJ, Yoon HK, Kim YH, Wang YP and Lim Y: Comparative genomic hybridization array analysis and real time PCR reveals genomic alterations in squamous cell carcinomas of the lung. Lung Cancer 55: 43-51, 2007.

19. Kang JU, Koo SH, Kwon KC, Park JW and Kim JM: Gain at chromosomal region $5 \mathrm{p} 15.33$, containing TERT, is the most frequent genetic event in early stages of non-small cell lung cancer. Cancer Genet Cytogenet 182: 1-11, 2008.

20. Pinkel D, Straume T and Gray JW: Cytogenetic analysis using quantitative, high-sensitivity, fluorescence hybridization. Proc Natl Acad Sci USA 83: 2934-2938, 1986.

21. Willenbrock H and Fridlyand J: A comparison study: applying segmentation to array $\mathrm{CGH}$ data for downstream analyses. Bioinformatics 21: 4084-4091, 2005.

22. Oshiro A, Tagawa H, Ohshima K, Karube K, Uike N, Tashiro Y, Utsunomiya A, Masuda M, Takasu N, Nakamura S, Morishima Y and Seto M: Identification of subtype-specific genomic alterations in aggressive adult T-cell leukemia/lymphoma. Blood 107: 4500-4507, 2006.

23. Kresse SH, Skårn M, Ohnstad HO, Namløs HM, Bjerkehagen B, Myklebost O, Meza-Zepeda LA: DNA copy number changes in high-grade malignant peripheral nerve sheath tumors by array CGH. Mol Cancer 7: 48, 2008.

24. Jardin F, Ruminy P, Kerckaert JP, Parmentier F, Picquenot JM, Quief S, Villenet C, Buchonnet G, Tosi M, Frebourg T, Bastard C and Tilly H: Detection of somatic quantitative genetic alterations by multiplex polymerase chain reaction for the prediction of outcome in diffuse large B-cell lymphomas: Haematologica 93: 543-550, 2008.

25. Nakaya K, Yamagata HD, Arita N, Nakashiro KI, Nose M, Miki T and Hamakawa H: Identification of homozygous deletions of tumor suppressor gene FAT in oral cancer using CGH-array. Oncogene 26: 5300-5308, 2007.

26. Flordal Thelander E, Ichimura K, Collins VP, Walsh SH, Barbany G, Hagberg A, Laurell A, Rosenquist R, Larsson C and Lagercrantz S: Detailed assessment of copy number alterations revealing homozygous deletions in $1 \mathrm{p}$ and $13 \mathrm{q}$ in mantle cell lymphoma. Leuk Res 31: 1219-1230, 2007.

27. Bashyam MD, Bair R, Kim YH, Wang P, Hernandez-Boussard T, Karikari CA, Tibshirani R, Maitra A and Pollack JR: Arraybased comparative genomic hybridization identifies localized DNA amplifications and homozygous deletions in pancreatic cancer. Neoplasia 7: 556-562, 2005.
28. Narayan G, Goparaju C, Arias-Pulido H, Kaufmann AM, Schneider A, Dürst M, Mansukhani M, Pothuri B and Murty VV: Promoter hypermethylation-mediated inactivation of multiple Slit-Robo pathway genes in cervical cancer progression. Mol Cancer 15: 16, 2006.

29. Hui AB, Takano H, Lo KW, Kuo WL, Lam CN, Tong CY, Chang Q, Gray JW and Ng HK: Identification of a novel homozygous deletion region at $6 \mathrm{q} 23.1$ in medulloblastomas using high-resolution array comparative genomic hybridization analysis. Clin Cancer Res 11: 4707-4716, 2005.

30. Kim SK, Ro JY, Kemp BL, Lee JS, Kwon TJ, Hong WK and Mao L: Identification of two distinct tumor-suppressor loci on the long arm of chromosome 10 in small cell lung cancer. Oncogene 17: 1749-1753, 1998.

31. Wozniak A, Sciot R, Guillou L, Pauwels P, Wasag B, Stul M, Vermeesch JR, Vandenberghe P, Limon J and Debiec-Rychter M: Array CGH analysis in primary gastrointestinal stromal tumors: cytogenetic profile correlates with anatomic site and tumor aggressiveness, irrespective of mutational status. Genes Chromosomes Cancer 46: 261-276, 2007.

32. Fujii H, Ichikawa K, Takagaki T, Nakanishi Y, Ikegami M, Hirose S and Shimoda T: Genetic evolution of alpha fetoprotein producing gastric cancer. J Clin Pathol 56: 942-949, 2003.

33. Derre J, Lagace R, Terrier P, Sastre X and Aurias A: Consistent DNA losses on the short arm of chromosome 1 in a series of malignant gastrointestinal stromal tumors. Cancer Genet Cytogenet 127: 30-33, 2001.

34. O'Leary T, Ernst S, Przygodzki R, Emory T and Sobin L: Loss of heterozygosity at $1 \mathrm{p} 36$ predicts poor prognosis in gastrointestinal stromal/smooth muscle tumors. Lab Invest 79: 1461-1467, 1999.

35. Van Dekken H, Alers JC, Riegman PH, Rosenberg C, Tilanus HW and Vissers K: Molecular cytogenetic evaluation of gastric cardia adenocarcinoma and precursor lesions. Am J Pathol 158: 1961-1967, 2001.

36. Fibach E, Treves A, Kidron M and Mayer M: Induction of differentiation in human myeloid leukemic cells by proteolytic enzymes. J Cell Physiol 123: 228-234, 1985.

37. Retrieved from: http://users.navi.net/ rsc/iet_txt.html (18 October 2009). 